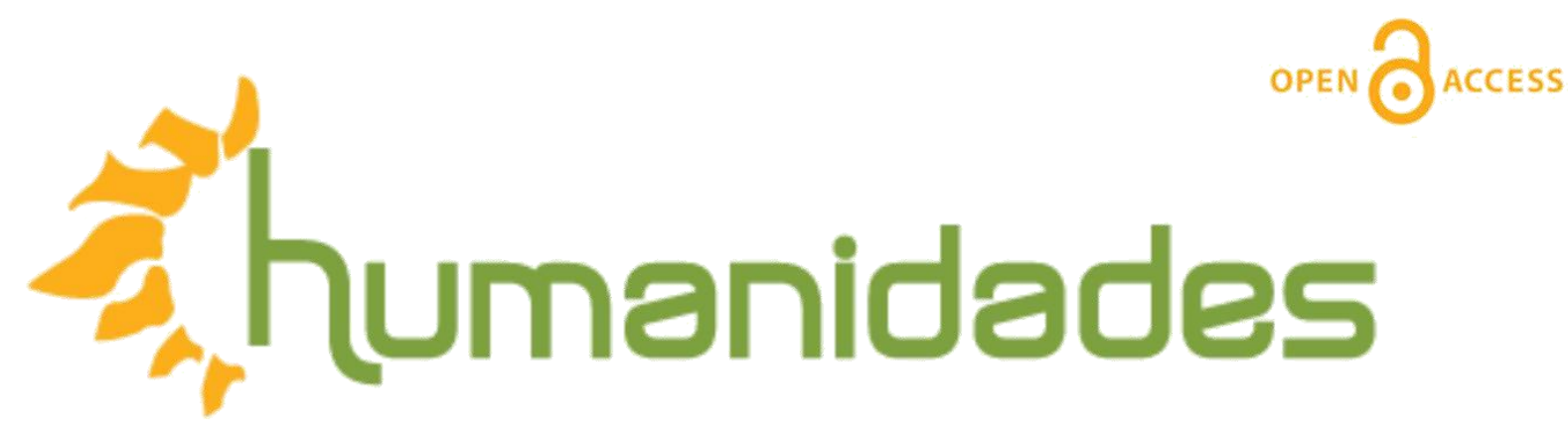

Revista de la Escuela de Estudios Generales, Universidad de Costa Rica

Julio-diciembre, 2017 • Volumen 7, número 2 • EISSN 2215-3934•

Recibido: 05-Abril -2017 Aceptado: 15-Mayo -2017

“El Lenguaje de los Tambores Batá, Dentro y fuera del Ritual de Santería"

DOI: http://dx.doi.org/10.15517/h.v7i2.29581

\title{
Manrique Méndez Vega
}

Profesor - Cátedra de Percusión, Escuela de Artes Musicales Universidad de Costa Rica. Correo electrónico: manriquemendez@ucr.ac.cr

Todos los derechos reservados. Universidad de Costa Rica. Esta revista se encuentra licenciada con Creative Commons. Reconocimiento-NoComercial-SinObraDerivada 3.0 Costa Rica.

Correo electrónico: humanidades@ucr.ac.cr / Sitio web: http://revistas.ucr.ac.cr/index.php/humanidades 


\title{
“El Lenguaje de los Tambores Batá, Dentro y fuera del Ritual de Santería"
}

\section{Resumen}

Desde los inicios en el aprendizaje de la música en cualquiera de sus especialidades, se habla de ella como un lenguaje por medio del cual se expresa y comunican ideas y formas de expresión que son reflejo de nuestras sociedades a través de cientos de años.

Dentro de la familia de instrumentos de percusión existe un grupo de instrumentos que plantean una relación directa con una sociedad en particular y que establecen un vínculo estrecho entre el ser humano y sus deidades en su grupo de creencias y costumbres fuertemente unidas a los tambores.

En este caso estoy hablando de los "Tambores Batá" (de la lengua Yoruba - Nigeriana Tambor). Estos instrumentos en su estado original funcionan como un grupo por si solos y en grupo de tres tambores. Los tambores Batá son tambores bimembranófonos que tienen forma de reloj de arena y sus nombres de pequeño a grande son: Iyá (tambor Parlante), Itótele (medio) y Okónkolo (Pequeño). Como en toda trilogía de tambores y en la usanza africana, se cree que el tambor más grande (Iyá) es el llamado a establecer la comunicación dentro de todo el ritual religioso en el cual éstos se utilizan.

Es así que con base en el modelo lingüístico de Ferdinand de Saussure, y en relación con la premisa que se establece con el lenguaje musical de los "Tambores Batá" como un sistema de comunicación; que podríamos pensar en un lenguaje sistematizado para esa comunicación. Se establecen similitudes del lenguaje entre humanos y Tambores Batá.

Palabras claves: Tambores Batá, Ritual, Lenguaje, El habla

\section{The Language of Bata Drums in and out of The Santería Ritual}

\begin{abstract}
From the beguining of any learnig process in music, we think of it as a language to express and communicate ideas, formats and forms of expression from all societies and through out hundreds of years.

Among the percussion instruments we can find a group of instruments that have a closed relationship with the religious traditions, in which human being and deities are closely attached. In this case, I am talking about the "Batá Drums" ( In Yoruba Language means Drum) The set of Batá drums work always in a group of three drums. These drums are double headed drums in a sand clock shape and their names from the bigges to the small are: Iyá - Itótele and Okóncolo. It is a performance practice in African drumming that the drums work togather, but the "Iyá" is the one that stablishes the communications between humans and deities in their ritual.

Based on the Linguistic model by Ferdinand De Saussure (French) and the idea of the stablishment of a language with the batá drums - as a communication system, we could think on a language with the batá drums by themselves. In this way we see similarities between both languages regarding a well stablished commuication system.
\end{abstract}

Keywords: Bata Drums, Ritual, language, Speech 


\section{Introducción}

Dentro del marco conceptual del modelo lingüístico de Ferdinand de Saussure (Lingüista suizo considerado el fundador de la lingüística moderna), encontramos diversos puntos que nos hablan de la comunicación humana por medio del habla. El tema de esta presentación en particular se ocupa de un trío de tambores ceremoniales que de acuerdo con las creencias del pueblo Lucumí en África "hablan", y por tanto puede ser que, luego de conocer simbolismos y aspectos históricos de estos instrumentos musicales, también sea posible establecer alguna similitud entre los conceptos de Saussure y el fenómeno lingüístico de estos tambores ceremoniales.

De acuerdo con Saussure, se presenta un principio dentro del lenguaje que desde cualquier punto de vista que sea visto, este es un "objeto doble" formado por dos partes, las cuales son interdependientes una de la otra. Con esto en mente, se plantea la dualidad opositiva; esta es la dualidad articulatoria acústica, la del sonido y del sentido, del individuo y de la sociedad, de la lengua y de la palabra, de lo material y de lo insustancial, de lo "memorial" (paradigmático) y de lo sintagmático, de la identidad y de la oposición, de lo sincrónico y de lo diacrónico, etc. En cada uno de estos ejemplos las partes no tienen valor por sí mismas y existe la contraposición de una con la otra.

(ver Fig \#1) De cualquier manera, logra gran significado la dependencia de las partes para el logro de un significado en lo que conocemos como lenguaje o forma de comunicación.

\section{Figura 1.}

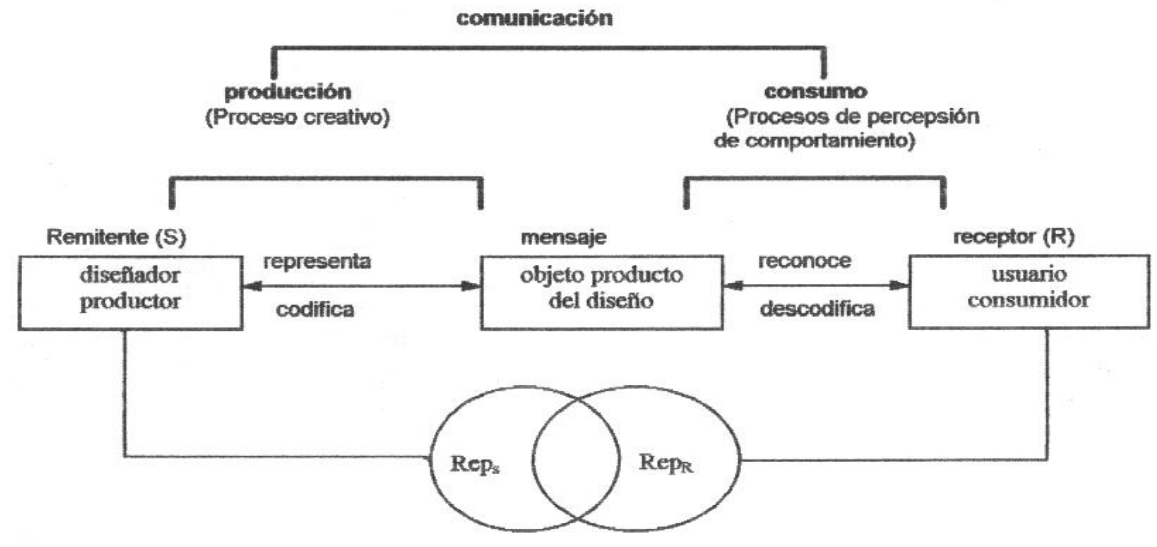

Fuente: Elaboración propia

En su forma más tradicional de ejecución, los tambores batá desarrollan una función muy similar como conjunto con su función y simbolismo dentro de la nación lucumí en África. De igual manera cabe pensar que la actividad en la cual se desarrollan los tambores batá, se desarrolla a mi criterio, un proceso que es conocido como la "Intertextualidad". (En el ámbito literario) Ámbito o concepto en el cual existe la coexistencia de dos o más textos. En otras palaras, la presencia efectiva de un texto en otro. 
Esto se basa en la teoría planteada por Mijail Bajtin y que es acuñada en por Julia Kristeva 1967. En ésta teoría la autora dice "Todo texto es la absorción o transformación de otro texto" Es acaso éste el caso de los tambores batá? Tomando en cuenta que éstos son mediadores y/o interlocutores del lenguaje entre nuestro mundo y el de los Dioses?

Desde los dos puntos de vista se plantea la forma en la cual un texto, idea o mensaje, es transmitido de un emisor a un receptor para su entendimiento y realización del ritual en el cual los batá están insertos y estableciendo una forma de comunicación.

Los tambores Batá fueron creados con fines religiosos. Cada vez que tratamos con asuntos de religión, existe un cierto misticismo en todos los objetos que relacionamos con ella, no importa cuál religión sea o de dónde venga.

El simbolismo es parte de lo que vuelve misteriosos e interesantes los instrumentos que se relacionan con la Santería y con sus ritos religiosos, sobre todo los instrumentos musicales que utiliza. Imitan el lenguaje de tal forma, que pueden comunicarse con la gente, los dioses y entre sí.

Las religiones africanas inmigraron a Cuba y posteriormente a New York hace relativamente poco tiempo, y con ellas una serie de objetos representativos de las filosofías de vida de esos pueblos.

La Santería, religión proveniente de Nigeria, y traída a Cuba por el pueblo Yoruba durante el esclavismo, utiliza en sus ceremonias los tambores Batá. Se trata de un grupo de tres tambores que se dice "articulan la fonética del leguaje Lucumí," del pueblo Yoruba. En el entendido de que los tambores "hablan", el tambor sagrado se utiliza para llamar o invocar a los dioses u "orichas", que no pueden negarse y deben acudir. Cada amarra de cuero, los materiales con que se construyen, cada sonido delicadamente ordenado, tiene una significación particular dentro del ritual de santería siendo éste religioso y cultural.

Aquellos dignos de tocar los tambores de los dioses se destacan por tener vastos conocimientos de su arte, que se ejecuta con todo respeto frente al panteón Yoruba y sus sacerdotes en primera instancia. Para los africanos el tambor habla el idioma del hombre y de los dioses, y la Santería conserva ese principio. Las ejecuciones son verdaderas conversaciones entretejidas por los instrumentistas.

Para aclarar todo este misticismo que envuelve a los tambores, existen datos sobre los conceptos religiosos que se manejan a su alrededor, algo de historia de su origen, lo complicado y simbólico de cada aspecto de su construcción, y la función social de los instrumentistas que los tocan. 


\section{La Familia de los Tambores Batá: (Su función en la conversación, simbolismo en la sociedad Yoruba)}

\section{Fotografía 1}

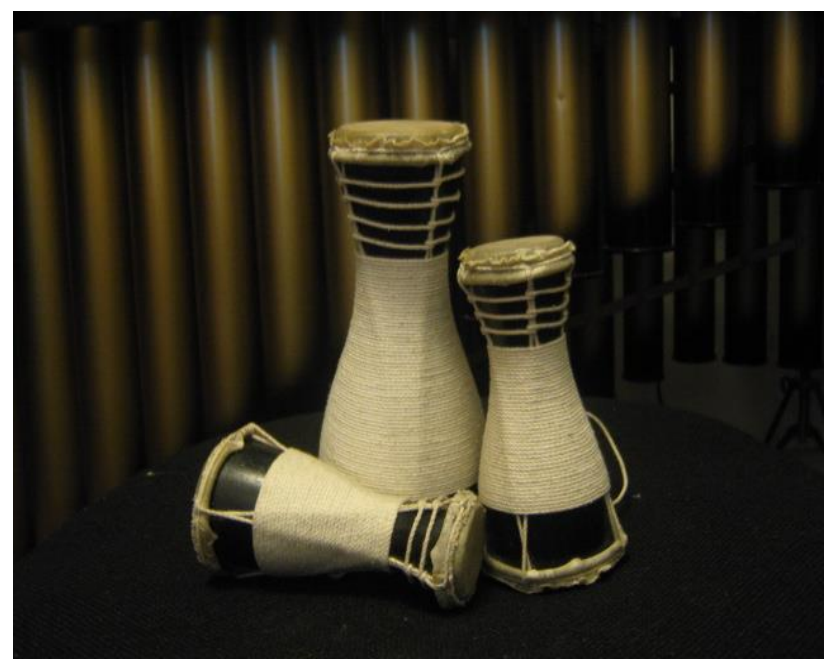

Tambores Batá

Fuente: Fotografía propia.

Los batá es un trío de tambores de forma clepsídrica, como relojes de arena; los tres son de diferente tamaño, pero tienen la misma forma. (Ver fotografía \#1) Para conocer éste trio de tambores en su contexto original debemos conocer las particularidades en su ámbito social también. Cada uno tiene dos parches de cuero, uno más pequeño que el otro, uno en cada "tapa del reloj". En realidad muchos consideran a los batá como un sexteto de membranófonos (Ortiz, 1965). Los instrumentos fueron concebidos para fines religiosos, pero los hay para fines meramente musicales. Todo depende del propósito, si reúnen las condiciones para ser consagrados o no.

Los tambores destinados a ceremonias religiosas deben tener una serie de requisitos: Deben construirse con ciertos materiales solamente. Cuando se construyen con los materiales adecuados y se afinan los parches con cuidado, producen un efecto de resonancia que hace pensar a quienes los escuchan, que el sonido de este trío es absolutamente embriagante y mágico. Pero de su construcción me ocuparé luego y con más detalle.

Los tres tambores son inseparables, y se tocan siempre en conjunto, como una familia: se les llama Omóaña o hijos del dios de los tambores. Los tambores consagrados se conocen como Añá, y los profanos como Ilú. El tambor más pequeño se llama Okónkolo u Omelé, y su función dentro del conjunto es más que todo la de tocar un ostinato rítmico mientras los otros tambores "conversan". El tambor de talla media se llama Itótele, y aquel encargado de tocarlo debe mantenerse alerta para que intercambie o resalte las impresiones (como el receptor en el lenguaje) del tambor mayor. (Conocido como el tambor principal -y/o parlante).

El tambor grande se llama Iyá o madre. Su papel de "madre" en esta familia de tambores es un símbolo de gran fuerza y de unión con la naturaleza (Amira y Cornelius, 1992). Solamente un iniciado de grandes conocimientos y gran poder toca el Iyá, porque es el que dirige toda la organización "tambor - parlante" del evento. A esta persona se le llama olubatá o jefe de los tambores, y debe 
saber "hablar" con su tambor como nadie (Ortiz, 1965). La responsabilidad es muy grande, puesto que llamar a los orichas es cosa seria y fundamental para que el resto de la ceremonia se lleve a cabo de la forma ideal. El valor musical, en estos casos, queda en un segundo plano, y a veces ni se toma en cuenta, puesto que lo más importante de estas ejecuciones es su trascendencia de comunicación y fuerza mágica, no su valor estético.

Los tambores deben hacer el encantamiento más fuerte y poderoso, no necesariamente más bello, por lo que los bataleros deben seguir estrictas reglas y ordenamientos preestablecidos con rigurosidad (Ortiz, 1965).

Sin embargo, la maestría y fervor al tocar, más el respeto que tienen los bataleros por su oficio, dan como resultado un hermoso, interesante y maravilloso espectáculo musical, razón por la cual el arte de los batá se ha extendido a otras regiones del globo.

Dentro del ritual de Santería los bataleros y sus tambores tienen su simbolismo familiar entre ellos también. Los tambores representan unidad, y los bataleros son parte de ese concepto. Pero no son hijos del tambor, sino que la mayoría prefiere pensar que se casan con ellos: el hijo producto de esta relación es el vigoroso y potente poder musical que emana del instrumento (Amira y Cornelius, 1992). Esto también se puede pensar como el texto interpretado por los interlocutores de la coversación establecida por dichos tambores o bien el proceso de intertextualidad según el propósito de la seremonia. Las jerarquías, como en todas las familias, también existen entre bataleros. Entre más experimentado y más poderoso, más importante y respetado es el músico. La asociación del tambor con el ejecutante es de suma importancia y se piensa que representan una sola entidad. El percusionista que dedica su vida a los tambores sagrados realmente busca ser uno con sus tambores; hay aprendices y toda una gama de rangos en medio, antes de llegar a ser maestro. Su razón de ser está más allá del simple hecho de la creación musical: tiene el poder de encarnar el poder mágico de llamar a los Orichas con su instrumento; creando el ambiente propicio de comunicación entre el hombre y los Dioses. Los Bataleros son la llave; son los conocedores de "la clave del lenguaje de sus instrumentos".

El ser batalero es ser alguien importante y destacado dentro de su comunidad, y se le respeta como tal. Cuando llega el momento de tocar para una ceremonia, se cede el lugar de privilegio, el tambor Iyá, al más respetado maestro olubatá. El siguiente en jerarquía toca el Itótele, por ser este el tambor que intercambia discursos con el Iyá; por ratos toca patrones repetitivos, pero debe estar atento para apoyar al Iyá. El tercero en jerarquía es el ancla rítmica, porque tocar Okónkolo no es tan sencillo, pero permite que el intérprete ponga atención a lo que hacen los otros dos y aprender.

Este concepto de unidad y codependencia en el proceder de los bataleros prevalece a través de todo el ritual y que se liga estrechamente con el modelo linguiístico ( objeto doble) de significación planteado por Saussure.

De ésta manera y volviendo al modelo lingüístico de Saussure se ha de entender que a no tiene significación en tanto no exista b y viceversa. En el plano musical esto toma sentido de la siguiente manera:

En las ejecuciones de tambores batá se emiten seis sonidos diferentes a la vez, pero existe lo que llamaré el canto del conjunto de tambores en su interrelación y así formular el lenguaje sonoro de comunicación. Este se da a nivel musical así como simbólico dentro del ritual ya que existen otros agentes como los cascabeles hacidos al tambor Iyá y que crea con su sonido el ambiente propicio para establecer la comunicación con los Dioses. 
El ritmo a continuación es conocido como "Chachá - Rocafú” y es utilizado como puente o transición entre uno y otro ritmo previamente asignado a diferentes deidades. ( ver figura \#2 y \#3 en reducción)

Figura 2.

\section{Cha chá Rocafú}

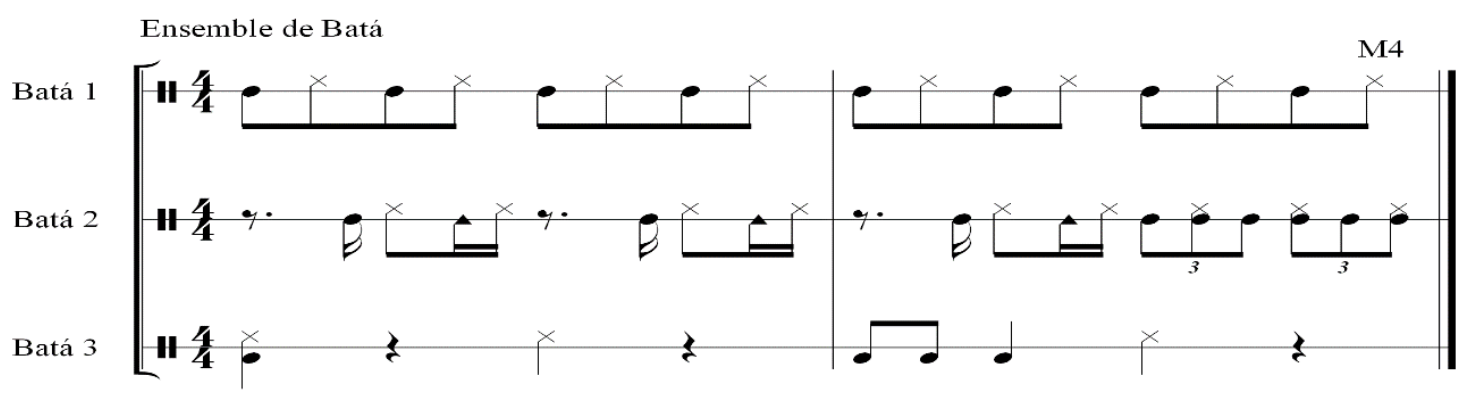

Fuente: Elaboración propia.

Figura 3.

Cha Chá Rocafú para tres Tumbadoras

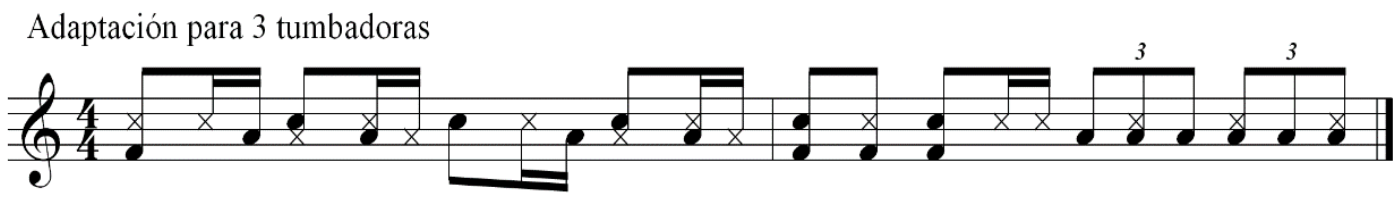

Fuente: Elaboracion propia. 


\section{Desde Nigeria, la religión Yoruba:}

\section{Fotografía 2. Tambores Modernos}

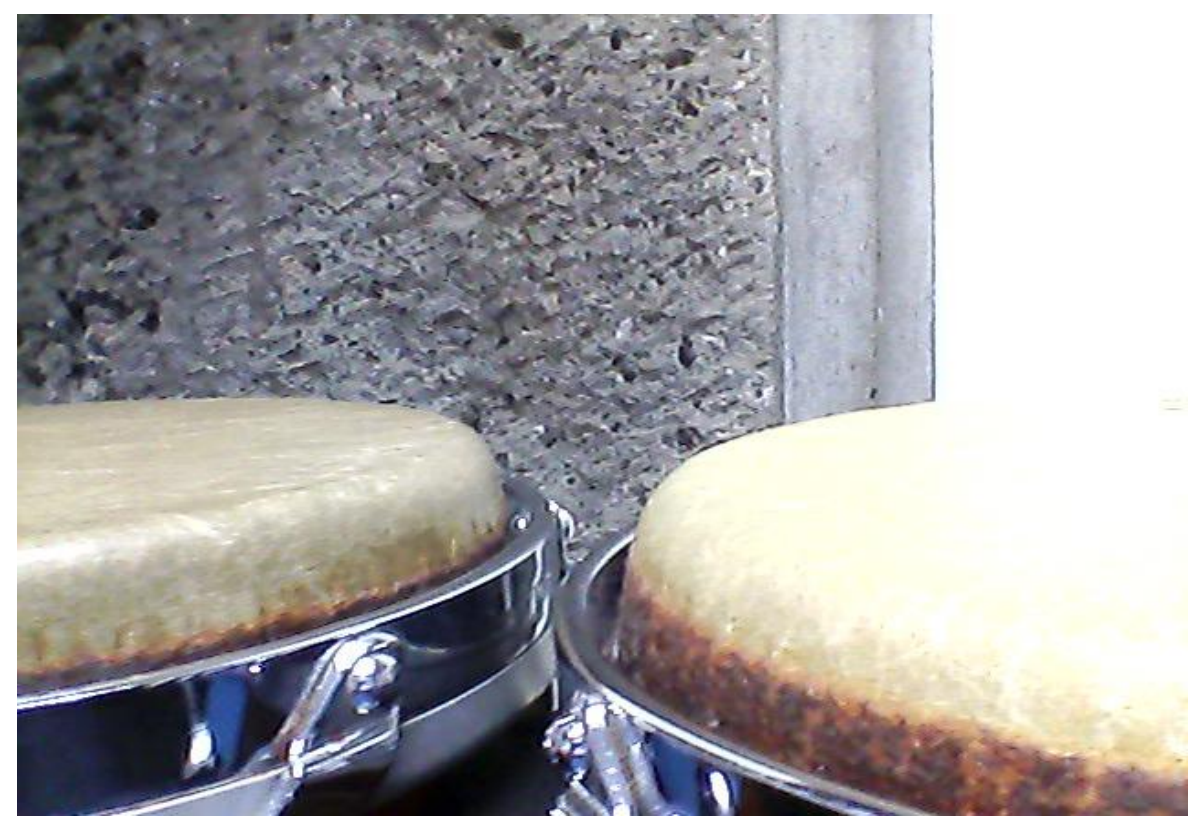

Fuente: Fotografía propia.

Los pueblos africanos utilizan los tambores para "hablar" con los dioses. El parecido de los sonidos percutidos del tambor con los sonidos de los idiomas africanos es notable y por ello siempre han servido para propósitos de comunicación a distancia: hasta con otros mundos. La presencia de los tambores en ceremonias de comunicación con los dioses u orichas es fundamental (Ortiz, 1965). Al parecer de nada sirven las palabras: es el tambor el que puede alcanzar a los dioses e invitarlos a venir. (Este es el "Médium")

El pueblo Yoruba, oriundo de Nigeria, reconoce su lenguaje en el canto de sus tambores: "El lucumí". La tradición nos dice que la trascendencia de instrumentos musicales como este trío de tambores, los Batá, radica en que vuelven el conjuro mágico en algo realmente poderoso y significativo, aumentando la fuerza mágica con el sonido rítmico de sus cueros (Ortiz, 1965). Para un Yoruba, acompañar sus oraciones con el ostinato rítmico de un tambor induce a un altísimo nivel de concentración y devoción; después de todo, cada palabra traducida al leguaje del tambor cobra nueva vida y se reviste de poder mágico para conversar con los Dioses. Igualmente no se deja de lado la posibilidad de un grado alto de transe por parte de los que participan en el ritual.

Hemos visto cómo existe la tradición de los pueblos africanos de comunicarse por medio de tambores, sobre todo a través de grandes distancias. Una especie de lenguaje religioso en clave es lo que se escucha cuando el olubatá tañe su tambor Iyá. En el idioma de los tambores africanos, cada persona importante tiene un nombre musical, pronunciable tan sólo por el tambor. Cuando se le llama por su oriki o nombre musical secreto, quienquiera que sea debe atender el llamado sin dudas lo más pronto posible. Son los tambores batá los que llaman a los orichas por sus oriki, y de una forma que sería totalmente imposible de ignorar. Cada uno de los orichas tiene su "llame" particular, y se deben tocar 
los 24 (hay dos orichas que tienen 2 llames) para convocarlos a todos y así establecer la conversación. (Ortiz, 1965).

\section{El aporte cubano a la religión y a la música:}

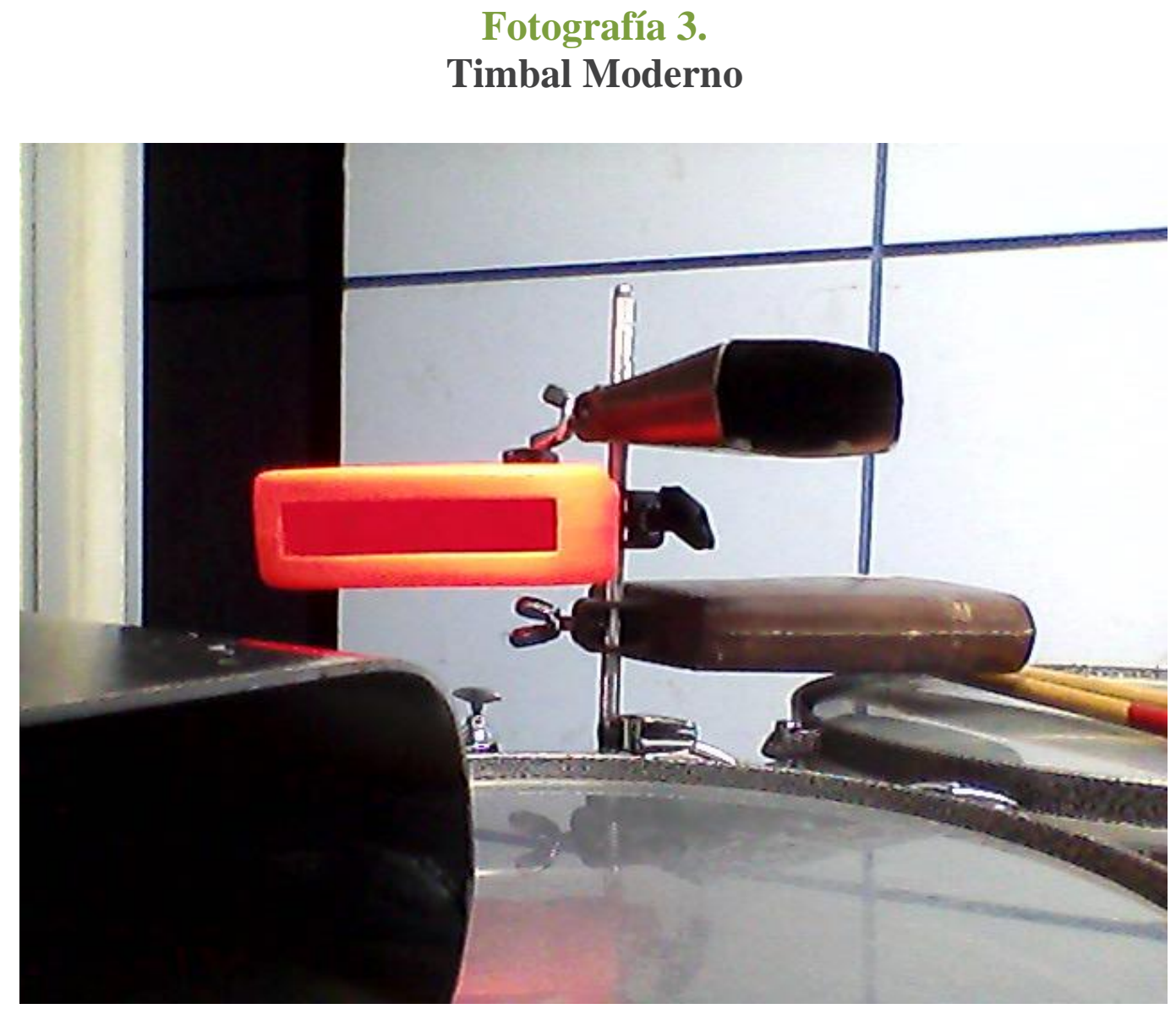

Fuente: fotografía propia

En la Santería Afrocubana cada uno de los 24 orichas o dioses simboliza una parte del creador Olorún. Sin embargo, el creador es inaccesible e incomprensible, por eso es que los humanos acuden mejor a los orichas, que son flexibles y comunicativos la mayor parte del tiempo. A veces son caprichosos, y tienen sus jerarquías, incluso entre ellos, por lo que se pelean frecuentemente. Pero los tambores pueden engañarlos y obligarlos a presentarse aunque no quieran. Después de todo, los tambores conocen su nombre secreto y su llame particular. El olubatá es el maestro que consigue, junto con sus compañeros, que los orichas no se resistan nunca a aparecer frente al necesitado (Amira y Cornelius, 1992).

Originalmente, el área donde se llevaban a cabo las ceremonias religiosas eran áreas boscosas en África. Al llegar a Cuba, se adaptaron los ritos en habitaciones especiales destinadas a las diferentes etapas de la ceremonia. Todo comienza en una habitación cerrada donde solamente el sacerdote o 
Babalao, el sujeto del rito, un ayudante y los bataleros tienen permitida la entrada. Esta habitación es llamada el Igbodu. La música es parte crucial puesto que no se puede contactar a los orichas sin los tambores, y se tocan los llames como letanías uno para cada dios, y hacen la veces de fonemas o interjecciones rápidas con una referencia a cada oricha; el orden es estricto.

El Iyá toca los llames, y el Itótele y el Okónkolo hacen ritmos simples: didé didé, que en lucumí significa "levántense" o "procedan" (Ortiz, 1965). Continúan con el Oru del Igbodu, que son toques con ritmos completos en ciclos para cada oricha, ya no son sólo referencias. Es como tocar un himno para cada oricha. Aquí no hay cantos, sólo los sonidos que sacan a sus tambores los expertos bataleros, rindiendo su homenaje mágico a los dioses y conversando con ellos. Se continúa luego al Eyá Eranla donde los iniciados, sacerdotes y funcionarios esperan ansiosos. Al final de la ceremonia se procede al Ibán Baló donde se encuentran mujeres, invitados y público. Los batá son protagonistas de principio a fin (Ortiz, 1965). La fundamentación del lenguaje establecido entre bataleros y Dioses representa el concepto de intertextualidad nombrado al principio de éste documento en el cual como acoté se apela a un texto anterior que se replantea según sea la ocasión de la ceremonia.

\section{En manos de iniciados: la construcción del tambor ceremonial:}

Los batá, en las manos de los iniciados, se cree que pueden conjurar, atrapar la naturaleza, imitar las tormentas, contener las fuerzas naturales, y por tanto el hechicero podrá dominarlas por medio del sonido de los tambores (Ortiz, 1965).

La creencia popular dice que los tambores sagrados deben incluir una serie de aspectos en su composición que no deben ser alterados. Sin embargo, y debido a lo complicado de estos procesos, los Batá sin consagrar se construyen hoy en día con técnicas modernas: madera en tablitas o fibra de vidrio, lo que facilita el darle la forma de reloj de arena, llaves de metal como las de las tumbadoras para afinarlos rápida y constantemente, y parches de fiberskin (imitación cuero), que se ven como cuero pero son de fibra artificial, más resistente y poco susceptible a la humedad.

Las mejoras no se aplican a los tambores ceremoniales porque cada parte del todo original tiene una razón de ser. Como los Batá son una familia que representa sobre todo unidad, cada tambor debe estar hecho de un solo tronco único, una sola pieza de madera enteriza para cada uno. En cuanto a las amarras y los parches, tanto en la Santería como en otras religiones africanas, los objetos ceremoniales deben estar hechos de elementos de algo que alguna vez estuvo vivo y que tengan trascendencia para el pueblo: la rama de un árbol sagrado, el cuero de un animal de sacrificio, los huesos de un antepasado, etc. Además, los tambores se cree que pertenecen al dios Changó, por lo que no podría construirse partes de ellos con metal, que se asocia con Ogún. La única excepción es el conjunto de cascabeles de bronce o tchaworo que se utilizan para decorar el Iyá. Los cascabeles son una referencia a Ochún, diosa del amor y la belleza, esposa favorita de Changó (Amira y Cornelius, 1992).

Los tambores contienen y transfieren poder mágico y sagrado; son para comunicarse, alabar y dar gracias. Son como actores que recitan su papel con orden. Este orden como menciono anteriormente, es invariable y dentro de su simbolismo es equivalente al ritual cristiano de la misa en el cual existe un orden predeterminado e invariable de igual manera. En el lenguaje de los tambores batá existe una 
interacción muy aguda para lograr la sincronización de los sonidos y de ésta manera el lenguaje puede ser entendido (hablando en cuanto a la lingüística) por el receptor de ese momento. (Uno de los Orichas) Cabe mencionar que en cuanto a comunicación, entre los tambores y los orichas se establece la comunicación sólo si esta está bien articulada entre los tambores en primera instancia.

\section{Referencias}

Amira, J. \& Cornelius, S. (1992). The Music of Santería. USA: White Cliffs Media Company.

Rodríguez, V.; Casanova Oliva, A.; Guanche Pérez, J.; Ramos

Venereo, Z.; C. Sáenz Coopat, C.; Vilar Alvarez, L.; Vinueza González, M. (1977). Instrumentos de la Música Folclórico-Popular de Cuba. Volumen 2. Centro de Investigación y Desarrollo de la Música Cubana. Editorial de Ciencias Sociales; La Habana. Cuba.

Peter, M. (1991). Essays on Cuban Music: North American and Cuban Perspectives. University Press of America.

Ortiz, F. (1965). La Africacanía de la Música Folklórica de Cuba. Cuba: Editora Universitaria. La Habana, Cuba.

¿Que es la Santeria?. (2017). Orishanet.org. Recuperado de: http://orishanet.org/ssanteria.html

Vizcaíno, M. (2017). Cuba. Una identitá in movimento - Los tambores Batá. Archivocubano.org. Recuperado de: http://www.archivocubano.org/vizcaino_10.html

BBC (s.f.). Religions - Santeria: Santeria deities. Recuperado de: http://www.bbc.co.uk/religion/religions/santeria/beliefs/orishas.shtml

Hanno, H., y Ehses, J. (2017). Semiótica y diseño en la página del profe. Lapaginadelprofe.cl. Recuperado de: http://www.lapaginadelprofe.cl/semiotica/semioticaydiseno/semdiseno1.htm 


\section{¿Cómo citar este artículo?}

Mendéz, M. (2017). “El Lenguaje de los Tambores Batá, Dentro y fuera del Ritual de Santería”. Revista humanidades, 7(2). http://dx.doi.org/10.15517/h.v7i2.29581 